
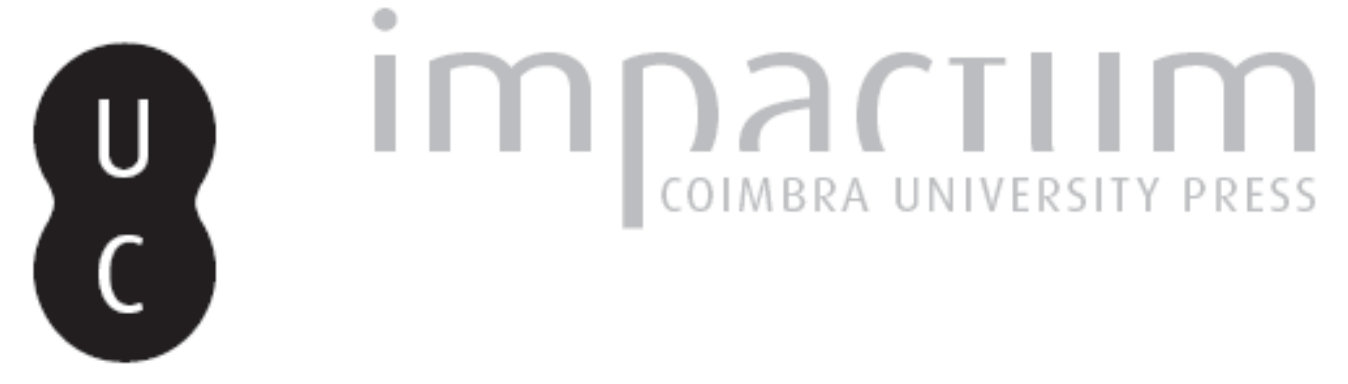

\title{
Estórias Portugal-África: concepção de um espaço digital de partilha
}

Autor(es): $\quad$ Soares, Francisco; Cruz, Maria Teresa

Publicado por: Imprensa da Universidade de Coimbra

URL persistente:

URI:http://hdl.handle.net/10316.2/39628

DOI:

DOI:http://dx.doi.org/10.14195/2183-5462_29_2

Accessed : $\quad$ 26-Apr-2023 13:16:01

A navegação consulta e descarregamento dos títulos inseridos nas Bibliotecas Digitais UC Digitalis, UC Pombalina e UC Impactum, pressupõem a aceitação plena e sem reservas dos Termos e Condições de Uso destas Bibliotecas Digitais, disponíveis em https://digitalis.uc.pt/pt-pt/termos.

Conforme exposto nos referidos Termos e Condições de Uso, o descarregamento de títulos de acesso restrito requer uma licença válida de autorização devendo o utilizador aceder ao(s) documento(s) a partir de um endereço de IP da instituição detentora da supramencionada licença.

Ao utilizador é apenas permitido o descarregamento para uso pessoal, pelo que o emprego do(s) título(s) descarregado(s) para outro fim, designadamente comercial, carece de autorização do respetivo autor ou editor da obra.

Na medida em que todas as obras da UC Digitalis se encontram protegidas pelo Código do Direito de Autor e Direitos Conexos e demais legislação aplicável, toda a cópia, parcial ou total, deste documento, nos casos em que é legalmente admitida, deverá conter ou fazer-se acompanhar por este aviso.

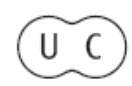




\section{Media Jornalismo}

\section{MÉDIA E COLONIALISMO(S)}




\title{
ESTÓRIAS PORTUGAL-ÁFRICA: \\ CONCEPÇÃO DE UM ESPAÇO DIGITAL DE PARTILHA ${ }^{1}$ \\ PORTUGAL-AFRICA STORIES: \\ DESIGNING A DIGITAL SPACE OF SHARING
}

\author{
FRANCISCO LIMA SOARES 2 \\ UNIVERSIDADE NOVA DE LISBOA \\ FACULDADE DE CIÊNCIAS SOCIAIS E HUMANAS \\ CENTRO DE ESTUDOS DE COMUNICAÇÃO E LINGUAGENS \\ 1069-061 LISB0A, PORTUGAL
}

FRANCISCOLIMASOARES@GMAIL.COM

MARIA TERESA CRUZ

UNIVERSIDADE NOVA DE LISBOA

FACULDADE DE CIÊNCIAS SOCIAIS E HUMANAS

CENTRO DE ESTUDOS DE COMUNICAÇÃO E LINGUAGENS

1069-061 LISB0A, PORTUGAL

TERESACRUZ12@GMAIL.COM

\begin{abstract}
Resumo
Um dos traços mais marcantes da cultura digital contemporânea é a constante partilha de memórias e experiências, vividas ou imaginadas. A presença ubíqua das redes sociais, associada a um desenvolvimento frenético do software e das aplicações que permitem captar e transmitir as mais variadas mensagens, alterou o modo como nos confrontamos com as imagens e narrativas que vão constituindo a memória cultural da nossa sociedade. Este artigo enquadra teoricamente e apresenta o projeto de investigação artística Estórias: Portugal-África que pretende responder a estes processos através da produção de um arquivo digital sobre experiências de entrosamento entre Portugal e África com raíz em histórias individuais, familiares e comunitárias, de migrações e cruzamentos culturais, provenientes da época colonial ou dos fenómenos pós-coloniais da miscigenação cultural e da afro-descendência. Neste texto, reflete-se em torno das dinâmicas transculturais possibilitadas pelos media, pelas redes de informação, pelas indústrias culturais e pelas artes contemporâneas mobilizadas por este projeto.
\end{abstract}

1 Menção de apoio: este artigo integra-se no projeto de investigação Estórias: Portugal-África apoiado pela Direção Geral das Artes, na categoria de Artes Digitais.

2 A concepção e responsabilidade científica do projecto de investigação bem como a redação relativa à sua apresentação, são da responsabilidade de Maria Teresa Cruz; a redação do restante artigo, incluindo a revisão de literatura, é da responsabilidade de Francisco Lima Soares. 


\title{
Palavras-chave
}

arquivo, arquivo digital, memória cultural, novos média, arqueologia dos média

\begin{abstract}
One of the most distinctive traits of contemporary digital culture is the uninterrupted sharing of memories and experiences both lived and imagined. The ubiquitous presence of social networks, along with the fast development of software and applications that enable the recording and transmission of many different messages has changed the way in which we confront the images and narratives that make up our societies' cultural memory. This article theoretically frames and describes the project Estórias: Portugal-África, which tries to be an answer to these processes by producing a digital archive about personal experiences that connect Portugal and Africa, experiences that can be rooted in family or community, in migrations and cultural crossings, in the colonial period or the post-colonial situations of cultural miscegenation. In this article I reflect on the transcultural dynamics made possible by the new media, the information networks and the practices of contemporary art mobilized for this project.
\end{abstract}

\section{KEYWORDS}

Archive, Digital archive, Cultural memory, New media, Media archaeology

\section{0 projeto Estórias: Portugal-África}

Este projeto centra-se nas narrativas e imaginários que apresentam e agem sobre a ligação contemporânea entre Portugal e África. Esta ligação, multigeracional e transversal na sociedade portuguesa, com raízes no passado colonial mas também em vários movimentos migratórios do período pós-colonial, decorre tanto de memórias como de vivências presentes e, ainda, dos fenómenos da afrodescendência, cada vez mais significativos no Portugal contemporâneo. Atualmente, esta ligação é também significativamente construída pelo discurso dos media, pelas indústrias culturais e pelas redes de informação, dos quais decorre um alargamento das experiências, das representações e do imaginário partilhados entre a cultura portuguesa e as culturas africanas lusófonas. Neste novo cenário, vamos assistindo à redescoberta da memória colonial por uma nova geração, assim como à reclamação e representação de novas "africanidades", decorrentes da afrodescendência e da miscigenação cultural. 0 contexto em que esta ligação e esta revisitação da memória se renovam e em que novas identidades se constroem é hoje, por sua vez, o contexto da globalização, onde os fenómenos da transnacionalidade e do entrosamento cultural são fortemente potenciados, mas não isentos de novas tensões, de novos fenómenos de estigmatização e de novos estereótipos.

0 projeto Estórias: Portugal-África visa mapear e investigar este imaginário em transformação, contribuindo para a sua consciencialização e análise, mas também para o seu enriquecimento, e por isso se assume como um projeto simultaneamente investigativo e votado à produção cultural e à criação. Seguindo a hipótese de Maurice Godelier, segundo a qual "o imaginário é pensamento, enquanto conjunto das interpretações que a Humanidade inventou para explicar a si mesma a ordem ou a desordem que reina no universo ou na sociedade", é do imaginário que partimos para apreender uma certa forma de pensamento, onde se enredam vivências, 
memórias, afectos, lugares comuns, e efabulações, acreditando que o imaginário desempenha um papel fundamental na determinação da própria ordem simbólica e também do que experienciamos como real.

Sendo na verdade "o domínio do Imaginário, um mundo real, mas composto de realidades mentais ou ideais confinadas ao espírito dos indivíduos (imagens, ideias, juízos, raciocínios, intenções)" diz ainda M. Godelier, "estas permanecem desconhecidas daqueles que habitam à sua volta, não podendo agir sobre a sua existência" a não ser através da sua exteriorização e partilha. (Godelier, 2007: 43). A partilha do imaginário é por isso condição e efeito da cultura, a qual se alicerça nele desde sempre, sob a forma de arquétipos e de imagens indispensáveis à construção da memória e da identidade, e ainda através das artes, que o enriquecem e transformam.

0 imaginário da ligação entre Portugal e África esteve, durante muito tempo, capturado por um certo tipo de imagens, as imagens do Portugal colonial, tendo vindo a ser, nas últimas décadas, reapresentado e desconstruído por diversas investigações. Estas têm trazido ao conhecimento público aspetos de uma história que importa de facto não apagar, e que vai sendo aliás acrescentada pelo desvendar de novos arquivos. A redescoberta desta memória por uma nova geração, isenta da responsabilidade por este passado histórico, confere um olhar à vez mais inquisidor, mas também mais estético, sobre estes arquivos, onde encontramos por sua vez uma imagética de enorme impacto, pela violência das suas implicações no plano político e humano.

Esta imagética colonial e o seu desarquivamento pós-colonial têm marcado assim muito impressivamente 0 imaginário da nossa relação com África, na sua vertente histórica e coletiva. Este processo deixa ainda na sombra dimensões vividas desta experiência, dispersas na enorme massa da memória vernacular, sempre mais heteróclita, diferenciada e em tensão, tanto com os véus da história como com os processos do seu desvelamento / julgamento. Nessa memória vernacular, que age diretamente e silenciosamente sobre a transmissão da experiência e se encontra dispersa pelo conjunto do tecido social, está inscrita, em toda a sua extensão a história coletiva, nomeadamente alguns dos seus não-ditos e também algo do que restará como seus interditos. Do apagamento traumático da violência à domesticidade e intimidade da experiência colonial, da dor à felicidade, tudo nesta memória vivida e vernacular é mais matizado a ambivalente, não encontrando por vezes estas histórias ligação de sentido com o relato historiográfico, cuja missão é o aprofundamento de uma verdade histórica, com mais ou menos contraditório. Passando sempre de algum modo por uma crítica das imagens ele implica também, consequentemente, uma certa erosão do imaginário, provocada pelo julgamento histórico.

Abrir a via das histórias, é abrir espaço à produtividade imaginária intrínseca da narrativa e a outra forma de ação da história sobre nós. A tecitura simultaneamente documental e ficcional da narrativa está carregada de uma significação antropológica ampla, na qual o imaginário é justamente um fio de ligação entre 0 individual e o coletivo, o presente e o passado, o próprio e o outro. A organização da experiência e da memória na forma narrativa é uma das formas fundamentais da produção de identidades, dos processos de subjetivação e de representação, produzindo ao mesmo tempo linhas de fuga imaginárias relativamente à própria ordem simbólica criada pela narrativa. 
A possibilidade de cada um contar a sua história representa, ao mesmo tempo, a abertura de um lugar de enunciação e de construção de um ponto de vista sobre a história dificilmente acessível de outro modo, sobretudo quando esta foi uma história de dominação. A possibilidade de uma história do outro e pelo outro demora por muitas razões a fazer-se e, por isso, é frequentemente através da literatura e das artes, guardiãs mas também transformadoras da memória, que se vai rompendo a captura do imaginário pelas cadeias da história. É nessa medida que o Atlas Estórias: Portugal-Africa se desenha como uma obra coletiva, um espaço poético aberto e participativo, mas convoca também especificamente artistas e autores, assumindo plenamente uma vertente de investigação artística e de curadoria.

Não haverá por certo uma reinvenção da ligação cultural entre Portugal e os países africanos lusófonos sem esta explosão do imaginário, alimentada pela memória e pela cultura do outro, por novas interseções criativas e também por novos lugares-comuns. Este é já na verdade o contexto presente, marcado por uma relação cada vez mais pregnante entre as cultura portuguesa e africanas, resultante de novas migrações, dos fenómenos da afrodescendência, dos processos da globalização e do estabelecimento de novas redes de comunicação. Todos estes aspetos contribuem a seu modo para a interpenetração cultural e para a emergência de novas narrativas pós-coloniais, num cenário não isento de problemas e de tensões, mas também marcado por novas virtualidades. 0 propósito deste projeto é 0 de contribuir para o reconhecimento e valorização desta nova condição, composta por identidades multiculturais complexas e por um entrosamento crescente de práticas, de formas de sociabilidade e de expressão, estendendo ao plano da imagem e do imaginário o papel integrador que tem sido sobretudo atribuído à língua enquanto ordem simbólica comum. ${ }^{3}$

\section{Estórias: Portugal-África, Memória e Arquivo}

0 que podem os Estudos dos Média trazer ao estudo das relações entre Portugal e o continente africano, que ainda não tenha sido desenvolvido por disciplinas como a História, os Estudos Pós-Coloniais, a Antropologia ou os Estudos Africanos?

As reflexões apresentadas neste artigo resultam da participação na gestão e conceção do projeto Estórias: Portugal-África, que se caracteriza, antes de mais, pela construção de uma plataforma digital. Esta é simultaneamente um arquivo digital de imagens e narrativas que ligam África e Portugal, e um objeto artístico que apela às dinâmicas de interação e participação associadas aos novos média e à arte contemporânea.

Assim, parte do princípio que uma discussão em torno dos dispositivos e práticas da nova configuração digital do arquivo na nossa cultura audiovisual e de software pode ser acompanhada de uma experimentação artística que mobiliza essas mesmas técnicas.

30 projeto Estórias: Portugal-África é uma iniciativa multidisciplinar do Centro de Estudos de Comunicação e Linguagens da Faculdade de Ciências Sociais e Humanas da UNL, em desenvolvimento desde Outubro de 2015, dirigido pela Prof. Maria Teresa Cruz e que envolve uma equipa de conceção e comunicação (CECL-UNL), uma equipa de desenvolvimento técnico e gráfico (Bagabaga Studios CRL), um conselho científico multidisciplinar e um conjunto de artistas plásticos, sob a curadoria de Ana Rito. 
Os arquivos tradicionais, que não prescindem hoje dos seus componentes digitais, constituem a ferramenta central a que recorrem as disciplinas supracitadas, na sua tentativa de conhecer os contornos desta relação. Este conhecimento assenta maioritariamente nos conteúdos destes arquivos. Mas os estudos dos média procuram compreender como é que as características do arquivo enquanto meio de comunicação técnico determinam a natureza das representações que recebe, transmite e processa.

Num panorama de constante troca de informação, sob a forma de narrativas e imagens, textos e sons, possibilitado pelo arquivo digital, com as concomitantes técnicas de registo e transmissão, o que pode ser inscrito e lido na memória cultural do século XXI?

Os arquivos tradicionais, os arquivos pessoais guardados e os arquivos ubíquos da contemporaneidade, todos coexistem através da digitalização. Como se pode mediar artisticamente esta informação, tornando-a sensível e legível para os portugueses e africanos que, hoje, constroem o seu imaginário comum?

Afirmam os editores de Representações de África e dos Africanos na História e Cultura, na introdução a esta compilação de textos multidisciplinar, que "a globalização que marca a contemporaneidade realça a urgência de promover o conhecimento entre os povos". "O olhar de África e dela sobre o mundo" exige um particular esforço de compreensão. Não só pelo complexo passado destes olhares, mas também em virtude da "intensificação dos fluxos de gente, bens e ideias, com relevo para as migrações transnacionais" (Rodrigues, 2011).

As representações que emergiram ao longo dos séculos podem ser investigadas no sentido de apreender os traços dos povos que as produziram, no modo como se olharam a si próprios e entre si. Mas é igualmente importante compreender que estas representações tiveram de se exteriorizar sempre e só assim se inscreveram na memória cultural geração após geração. E nesse sentido, estas representações não só se socorrem do aparato simbólico da cultura, como dos dispositivos e práticas que as mediaram tecnicamente. É também pelas técnicas que compreendemos o Homem.

Olhando a nossa história e recuperando uma das máximas de McLuhan, as novas formas digitais de mediação simbólica serão necessariamente responsáveis por mudanças no conjunto da experiência contemporânea ${ }^{4}$. Na forma como agimos e como nos concebemos a nós mesmos e aos outros. Os meios de comunicação atuais desencadeiam, necessariamente, um novo conjunto de representações.

A questão não é, pois, como podemos utilizar os média para investigar a história das relações entre Portugal e África. Mas sim, como podemos pensar os novos média, tais como 0 arquivo digital, de modo a que este possa mediar um conjunto de experiências que promovam o reconhecimento da nossa identidade multifacetada. Esta investigação, ainda em curso, em torno dos novos média inclui uma vertente de experimentação e concretização sob a forma de uma plataforma online. Entre 0 arquivo e a partilha de histórias, este espaço transindividual e poético tem como objetivo possibilitar tecnicamente o registo, transmissão e processamento das imagens e narrativas, do passado e do presente, que compõem o nosso imaginário comum. Concomitantemente, prossegue o seu estudo dos média, ao questionar as

4 As mudanças sociais, políticas, psicológicas, económicas, entre outras, provocadas pelos média eletrônicos guiam o seminal texto de McLuhan (McLuhan, 2008). 
técnicas - os dispositivos e as práticas - que a cada momento ligam simbolicamente experiência e memória. ${ }^{5}$

Que representações de África e de Portugal, dos africanos e dos portugueses, podem hoje emergir num arquivo digital?

\section{Memória Cultural e Arquivo}

Quando hoje falamos do arquivo ainda é possível que nos estejamos a referir àquela que foi a sua primeira definição culturalmente disseminada, nomeadamente a do arquivo como monumento. Há mais de dois mil anos, já os romanos depositavam no interior do templo de Saturno os documentos e objetos que consideravam ser de extrema importância para o estabelecimento da sua história, para a oficialização da sua autoridade e para a consolidação do seu legado. Neste se guardavam insígnias e tratados, decretos do Senado, documentos que davam conta das finanças públicas ou as moedas que, desde Júlio César, imortalizavam igualmente 0 retrato do imperador. 0 arquivo era, numa primeira fase, indistinguível do tesouro público (Parikka, 2012: 114). Aos objetos e documentos que deviam ser preservados como testemunho da cultura e do mundo estava associada uma ideia de preciosidade, refletida simultaneamente nos materiais raros que eram utilizados e nas características físicas deste espaço. 0 espaço murado e protegido do arquivo delimitava física e simbolicamente a lei, ou seja, o conjunto das inscrições que as sociedades humanas consideravam indispensáveis para a manutenção e gestão da ordem social. 0 arquivo era, como tal, uma ferramenta do poder, materializada como monumento público. Mas também delimitava um conjunto de ideias e valores que deviam ser transmitidos à posteridade, face à efemeridade de tudo aquilo que excluía do seu espólio. 0 arquivo era já, neste sentido, um médium, criador de mementos para as gerações futuras.

0 arquivo na sua forma monumental, que se prolonga de um ou outro modo até aos nossos dias, sobretudo através dos museus e das instituições ligadas à herança cultural, acumulava em si funções de gestão e celebração do Império pela informação preservada materialmente. 0 arquivo é, desde há muito, uma das principais ferramentas de armazenamento e classificação da experiência (Parikka, 2012: 113-4). ${ }^{6}$

Só no século XIX estaria completa a primeira alteração drástica do conceito, configuração e funcionamento do arquivo. Apesar de documentos e objetos muito singulares continuarem a ser uma prioridade (que começa a ser transferida para essa outra criação do século, o Museu), as novas possibilidades de registo e um progressivo desejo de racionalização das sociedades leva à concepção burocrática do arquivo, que desencadeará, já no século XX, a sua teorização moderna (Parikka 2011: 114).

5 Entre as iniciativas do projeto contam-se a construção de uma plataforma multimédia colaborativa (ainda em fase de desenvolvimento), que recorre às novas práticas mediais características das novas redes de informação e à programação de software para a visualização e pesquisa de dados, a produção de uma série de obras digitais por parte de artistas plásticos e a organização de um dicionário crítico do projeto, a cargo de um conselho científico multidisciplinar.

6 Jussi Parikka segue de forma muito próxima a trajetória histórica do arquivo enquanto médium proposta por Cornelia Vismann, autora de uma das poucas obras a discutir aprofundadamente a relação entre a lei e os meios de comunicação (Vismann, 2008). 
Cada cidadão passará a inscrever-se na memória da sua cultura sob a forma de documentos, identificações e exames que o classificarão de acordo com os parâmetros normativos que regem a sociedade. 0 arquivo passa, pois, a reunir o conjunto de dados que ligam cada indivíduo ao sistema em que se insere, calculando a ordem das suas integrações e desvios. Enquanto médium, 0 arquivo diferencia-se em arquivos tão variados como os hospitalares, escolares, jurídicos, prisionais ou corporativos. Desta viragem burocrática desviam-se os Museus, que enquadram os arquivos numa situação expositiva, e os arquivos pessoais que obedecem, antes de mais, aos afetos do arquivista. Com este primeiro alargamento do arquivo até à sua concepção burocrática, um campo muitíssimo vasto de informações passa a ser acumulado e preservado, pelos governos e instituições, na convicção de que nele reside a resposta racional a um mundo cada vez mais convulso e caótico. 0 arquivo responde, desde o século XIX, ao mundo disperso das massas. E torna-se, por isso, o médium necessário ao funcionamento burocrático das instituições, academias e corporações que acreditam poder englobar e sistematizar logicamente todos os aspetos relevantes da experiência humana e do funcionamento das sociedades.

Pode dizer-se, então, que o arquivo é uma forma de consolidação da memória cultural das sociedades humanas ${ }^{7}$, que preserva as informações relevantes para uma descrição de cada momento histórico e, simultaneamente, um instrumento de gestão do presente, que autoriza o poder pela exclusividade, veracidade e facticidade dos seus conteúdos.

\section{O Arquivo e o Discurso}

Foi Michel Foucault quem, já na segunda metade do século XX, alargou o conceito de arquivo para lá das suas fronteiras monumentais e da sua reticulação burocrática. Tendo assistido ao linguistic turn e pertencente a um meio intelectual extremamente influenciado pelo estruturalismo, Foucault terá pressentido que a confiança cega na instrumentalidade do arquivo devia ser questionada. Só assim podemos conceber 0 arquivo como uma invenção ou técnica cultural que autoriza o estabelecimento da realidade face àquilo que exclui e preserva. 0 arquivo, díriamos na terminologia de Bernhard Siegert, refere-nos a um conjunto de "operações ônticas" ${ }^{8}$.

Se a nossa memória cultural se objetiva na textualidade do arquivo, no qual lemos o que realmente teve lugar, podemos afirmar que só aquilo que pode ser inscrito e incluído nesse "espaço" se cimenta enquanto realidade. Uma das ideias transformadoras de Foucault foi a de que 0 alcance do arquivo enquanto médium abarcava a experiência de cada um, apesar dos limites de acesso impostos no caso de espaços físicos de arquivo. 0 discurso, ou seja, as possibilidades enunciativas disponíveis a cada momento numa cultura definem aquilo que pode ser inscrito e, por isso,

7 Seguimos aqui a definição de memória cultural proposta por Leroi-Gourhan, segundo o qual esta constitui o conjunto das exteriorizações que permitem uma memória coletiva, e para a qual contribuem as dimensões "animal", "humana" e "artificial" da memória. Leroi Gourhan traça também um trajeto pelas formas de memória cultural que derivam dos seus diferentes momentos históricos de aparelhamento técnico. (Leroi-Gourhan, 2002: 57-67)

8 Para uma descrição da ontologia dos média enquanto técnicas culturais, consultar Winthrop-Young, 2013. 
preservado. 0 arquivo, para Foucault, perde toda a sua territorialidade, pois que funciona em permanência na atividade discursiva dos seres humanos ${ }^{9} .0$ arquivo é, neste sentido, uma ferramenta conceptual (materializada nos mais diversos dispositivos, técnicas e práticas) que a cada momento autoriza o que pode ser dito, e por isso 0 que pode ser inscrito. 0 arquivo é, segundo Foucault, o conjunto dos discursos que, baseados na nossa memória cultural, nos permitem estabelecer a realidade na qual comunicamos, e que assim governam os nossos modos de pensar, agir e exprimir.

É precisamente esta visão alargada do arquivo que propiciará uma Arqueologia do Saber: a caracterização e descrição dos discursos possíveis a cada momento, dos seus confrontos e desdobramentos, das suas admissões e exclusões. A necessidade de recorrer ao arquivo para confirmar a continuidade dos acontecimentos históricos é substituída pela reflexão em torno dos discursos que, descontinuamente, estabeleceram a realidade e historicidade das nossas infinitas experiências do mundo através do médium do arquivo. Torna-se claro que 0 arquivo é o que define, de uma forma muito mais profunda do se suspeitava, o acesso à memória cultural da nossa espécie.

Em 1981-82 Foucault daria um curso no Collége de France, posteriormente publicado no volume A Hermenêutica do Sujeito, em que refletiu sobre o "cuidado de si" na Grécia de Platão, na Roma de Marco Aurélio e Séneca, na transição para o Cristianismo. 0 "cuidado de si" abarca um conjunto de processos de subjetivação, que podem ser entendidos como as relações entre o "eu" e a figura discursiva do "si mesmo" ou, mais precisamente, como os modos de o "eu" se posicionar no seio de uma cultura.

0 "si-mesmo" que encontramos nas Cartas a Lucílio, por exemplo, reporta-nos a sujeitos instituídos numa época, num espaço, no seio de uma sociedade, enfim numa cultura em que o "cuidado de si" é um dos dispositivos centrais de subjetivação. Mas é possível pensar processos de subjetivação no âmbito de culturas em que 0 "cuidado de si" não ocupa esse papel. Em que o sujeito é engendrado por outros discursos, provenientes de outras configurações do arquivo.

Qualquer subjetivação, nesta perspetiva, depende de dispositivos, técnicas e práticas que operem as passagens entre a experiência individual e o domínio da memória cultural, e que tanto podem ser conceptuais como materiais. Os sujeitos possíveis num dado momento decorrem, por isso, das possibilidades de aparelhamento do indivíduo ao sistema de sentido em que participa. Os sujeitos são fruto do arquivo, que medeia a sua interação com a memória cultural.

Desta relação com o arquivo - deste processo de subjetivação - resultam materializações do "eu" no plano discursivo que permanecem como documentos, rastos de uma cultura. Artefactos que são vestígios discursivos: experiências individuais do mundo mediadas através do que pode ser dito e inscrito. As manifestações semióticas do "eu" assumem sempre uma qualquer materialidade, porque exigem a linguagem em que se exteriorizam.

Neste ponto, faz sentido retomar uma passagem específica da "Hermenêutica do Sujeito" em que Foucault procura explicitar as condições necessárias para a

9 Como clarifica Fernando Cascais na sua introdução à Arqueologia do Saber, os discursos são a priori históricos e "os enunciados são acontecimentos, com as suas condições e o seu domínio de aparecimento, e coisas que comportam a sua possibilidade e o seu campo de utilização. Aos sistemas de enunciados propõe-se Foucault chamar-Ihes o arquivo." (Foucault, 2014: 20-1) 
existência de uma cultura. Isto é, as condições em que se pode dar a participação do indivíduo num sistema simbólico comum, desencadeando processos de subjetivação. Estas, de acordo com Foucault, podem ser sistematizadas em quatro pontos (Foucault, 2006: 220-1):

i)" [Que exista um] Conjunto de valores que têm entre si um mínimo de coordenação, de subordinação, de hierarquia."

ii) "Que estes valores sejam dados como sendo ao mesmo tempo universais, mas não acessíveis a qualquer um"

iii) "A fim de que os indivíduos atinjam estes valores, são necessárias certas condutas, precisas e regradas. (...) São necessários esforços e sacrifícios. (...) é necessário mesmo poder consagrar a vida inteira a estes valores para ter acesso a eles."

iv) "[Que] 0 acesso a estes valores seja condicionado por procedimentos e técnicas mais ou menos regrados, que tenham sido elaborados, validados, transmitidos, ensinados, e estejam também associados a todo um conjunto de noções, conceitos, teorias, etc., enfim, a todo um campo de saber."

0 "cuidado de si" articula-se, pois, com um conjunto de valores hierarquizados, através de práticas e técnicas regradas, no interior de um campo de saber comum, passível de ser transmitido e ensinado. 0 "cuidado de si" marca uma forma, documentada e registada como texto - no Alcibíades de Platão, nas cartas de Séneca a Lucílio ou nas meditações de Marco Aurélio -, de cruzar uma experiência individual do mundo e a experiência cultural da vida em sociedade, que definirá um tipo particular de sujeito. Os processos de subjetivação que esta hermenêutica descreve fundamentam-se no discurso escrito, em artefactos textuais.

Ao retomar as quarto condições para a existência de uma cultura enumeradas por Foucault, verificamos que nenhuma delas implica necessariamente um arquivo textual. São exigidos, apenas, elementos dessas regras e práticas que apontem para um campo estruturado de valores transmissíveis, isto é, portadores de significado. Elementos que tenham retido os vestígios de um sentido (mesmo que indecifrável, como é o caso da maioria das inscrições pré-históricas, por exemplo). São as materializações de uma cultura, isto é, são objetos que permitem a exploração arqueológica dos valores, das práticas, das técnicas e dos conceitos. ${ }^{10}$

0 Arquivo para a Arqueologia dos Média

A arqueologia dos média é uma corrente dos Estudos dos Média que procura adaptar o método arqueológico de Foucault não só aos discursos na sua forma tex-

10 Podemos dizer que Foucault aponta para estes outros elementos do discurso, que não se constituem como episteme textual, numa secção da arqueologia denominada "Outras Arqueologias" (Foucault, 2014: 248-9) 
tual, mas à sua mediação pelos dispositivos técnicos de registo e transmissão $0^{11}$. A nossa memória cultural está repleta de inscrições que não dependem somente do arquivo textual. A técnica, através dos seus dispositivos e práticas, define (de forma cada vez mais intensa e total) os nossos processos de subjetivação. A arqueologia dos média procura descrever os meios de comunicação, do mesmo modo que a arqueologia do saber descreve as formações discursivas. Seria impossível tentar compreender as formas de inscrição e leitura que sustêm a nossa cultura sem refletir acerca dos dispositivos técnicos e das práticas envolvidos nessas mediações simbólicas. Os nossos processos de subjetivação são, antes de mais, técnicos.

A arqueologia dos média é um empreendimento historicamente empírico que investiga o funcionamento dos meios de comunicação (Parikka, 2012: 113). Não só na sua estreita relação com a cultura em que estes se inseriram ou inserem, mas através de uma experimentação com esses mesmos meios, que os liberte do seu enquadramento exclusivamente "histórico"12.

\section{ARquivo Digital}

0 desenvolvimento das tecnologias de mediação digitais desencadeou mudanças profundas na concepção que fazemos do arquivo, que por este mesmo motivo será um dos principais tópicos da arqueologia dos média.

Monumento, burocracia e discurso: três formas progressivas de conceber o arquivo, à medida que este foi perdendo os seus contornos, até abarcar, na definição de Foucault, todas as mediações simbólicas entre a memória cultural e os sujeitos de uma cultura. A arqueologia dos média coloca a seguinte problemática: como repensar o conceito e práticas do arquivo na era dos média audiovisuais e do software? (Parikka, 2012: 113)

Na modernidade, e mais do que nunca na era digital, a quantidade de informação produzida, transmitida e armazenada aumenta exponencialmente, a par e passo com desenvolvimentos de ordem técnica (por exemplo, a capacidade de captar e fazer circular imagens).

Os média que nascem a partir do computador digital - os chamados novos média - acrescentam ao conceito de arquivo a capacidade de processamento técnico da informação. As características essenciais dos meios de comunicação, segundo Kittler - armazenamento, transmissão e cálculo ${ }^{13}$ - ficam assim reunidas num só dispositivo, capaz de traduzir qualquer mediação segundo um código binário, capaz de transformar um média em qualquer outro. A digitalização é, possivelmente,

11 Outras correntes contemporâneas dos Estudos dos Média investigam de que forma as características técnicas dos nossos dispositivos e práticas digitais nos constituem como "sujeitos". Nos Estados Unidos encontramos os Software Studies liderados por Manovich (para uma descrição pormenorizada, ver a introdução a Manovich, 2013). Já na Europa é de referir a Teoria dos Média Alemã (para uma explicação e crítica deste termo consultar Siegert, 2013).

12 Para arqueologias dos média que salientam esta dimensão de experimentação e prática consultar o trabalho de Wolfgang Ernst e Erkki Huhtamo.

13 Esta é uma sistematização recorrente na obra de Friedrich Kittler, extremamente influente em todas as correntes dos Estudos dos Média que abordam o poder ontológico que resulta das características materiais e operativas dos meios de comunicação técnicos. 
um momento de total desterritorialização, ou pelo menos de dispersão do arquivo, porque os discursos não só são mobilizados por todos, como co-existem sob um mesmo tipo de formalização, permitido pelas nossas máquinas (quase) universais, idealizadas por Alan Turing.

Ante este panorama contemporâneo, de que forma se deve conceber a relação entre 0 arquivo e a memória cultural?

A nova instabilidade do arquivo, que acompanha as mais diversas formas de armazenamento e transmissão, para o qual todos contribuem e que passou a incluir condições de acesso muito mais complexas, exige que 0 arquivo seja concebido como um constante processo de inscrição e leitura ${ }^{14}$. Uma arqueologia dos média avançará as seguintes questões: Que implicações têm estas novas práticas e discursos do arquivo para a nossa conceção de herança e memória cultural? Ou, revertendo a questão, como podemos pensar o papel do arquivo e do museu em culturas do software? 0 que significa e como podemos arquivar uma cultura feita de processos técnicos e sociais?

Em Programmed Visions, Wendy Chun, uma das autoras-chave da corrente dos Estudos de Software, reflete acerca da associação que a nossa cultura tem feito entre memória e armazenamento. Olhamos o computador digital como um instrumento capaz de armazenar a totalidade das inscrições que produzimos. Mas, e em primeiro lugar, esquecemos que também os elementos digitais são preservados sob uma base material, que inclui servidores e outros tipos de hardware capazes de proceder à transmissão e leitura das inscrições. São precisos objetos que nos permitam fazer correr os programas, são exigidos processos técnicos capazes de executar esta forma de memória. 0 arquivo como software não memoriza a totalidade da nossa experiência. Armazena inscrições (algumas delas instruções) que podem desvanecer e que permitem que o presente se caracterize como um "efémero que perdura". (Chun, 2011: 167-173)

Por outro lado, os tipos de informação armazenados no arquivo passaram a incluir , desde a gravação sonora e do cinema, um elemento temporal, que introduz uma dimensão temporalmente crítica no arquivo. Ou seja, o que se preserva são também objetos com uma duração. Segundo Wolfgang Ernst, o novo regime de memória cultural caracteriza-se por um presente que, enquanto categoria temporal, se bifurca numa multiplicidade de operações "microtemporais". 0 presente não é um "agora" estável, mas um processo que na nossa cultura dos média técnicos se define através de processos de software, streaming, codificações e descodificações de dados, ou outras formas de manipular os fluxos de dados enquanto processos temporais (Parikka, 2012: 123). A informação não é estável, o que liga intimamente o regime de processamento e questões relacionadas com a memória. Diz Ernst que "0 arquivo multimédia lida com media verdadeiramente baseados no tempo (que são imagens e sons), existindo cada imagem e cada som apenas num momento discreto no tempo. Congelar uma imagem eletrónica significa congelar o seu ciclo de renovação (refresh)" (apud, Parikka, 2012: 116-7).

14 "Apesar de a função tradicional do arquivo ser a de documentar um acontecimento que teve lugar num tempo e lugar específicos, a ênfase do arquivo digital passa a ser a regeneração, (co-)produzida pelos utilizadores online de acordo com as suas necessidades." (Ernst, 2013: 95) 
Finalmente, 0 armazenamento compulsivo de inscrições não implica a sua verdadeira inclusão numa memória dita cultural. A ameaça inerente ao arquivo digital não tem tanto que ver com os objetos ou os discursos que exclui, mas com a abundância de informação que é, hoje, capaz de armazenar. Antes de mais, coloca-se a questão do mapa de Borges. No limite, se todas as nossas ações forem registadas e armazenadas, 0 arquivo acabará por coincidir com a experiência ela mesma (Borges, 1982). Se não conseguimos navegar por completo a nossa experiência, passará a resposta pelo armazenar de todas as experiências, de todos os indivíduos do mundo?

Como lemos este arquivo que nos ultrapassa completamente? Só a inteligência artificial é hoje capaz de lidar com a quantidade de informação registada e armazenada. Este sublime informático é para nós ilegível na sua totalidade, e só pelo auxílio das nossas ferramentas digitais ele pode começar a ser inteligível. A inteligência artificial pode não "sentir" ou "pensar" como o humano, mas ultrapassou-o, irreversivelmente, nas suas capacidades de cálculo. A nova configuração do arquivo, que se refere mais ao gesto de arquivar do que ao arquivo delimitado ${ }^{15}$, não garante que tudo aquilo que se armazena devenha memória. Na verdade, só 0 gesto de constante re-atualização de um conjunto de dados pode garantir que estes são lidos no plano cultural e não desaparecem no mar informacional que hoje se acumula ilimitadamente. Sem esta re-atualização, que é no fundo a nossa capacidade de conferir sentido a uma inscrição pela sua recorrente leitura, podemos esperar apenas que essa informação seja agrupada em leituras técnicas do arquivo. Quem nos lê nos grandes números da big data - as máquinas que calculam e processam as nossas inscrições - lê-nos com o propósito de nos otimizar enquanto consumidores, de nos prever politicamente, de decidir racionalmente ante números que não estão ao alcance da nossa própria racionalidade, mas apenas dos detentores dessas poderosas ferramentas de cálculo, como é o caso das empresas de Silicon Valley, entre as quais se contam a Google ou o Facebook (Chun, 2008). Apesar de todas as promessas a que está associada, a atual memória técnica do arquivo conduz a processos de subjetivação cuja relação com a memória cultural que os engendra é fundamentalmente opaca. 0 desenvolvimento do software, em particular, é devedor de concepções da memória oriundas da Biologia e da Genética que, apesar de lidarem com a inscrição e processamento de informação, não nos permitem conceber a mobilização de sentido envolvida nestas mediações. É aí que as humanidades digitais podem contribuir para uma análise dos meios técnicos de informação que envolvem processos arquivísticos.

Questionar o conceito de arquivo equivale também a tentar compreender os modos de inscrição da informação e da cultura, no momento em que novas formas da economia e do capitalismo enquadram decisivamente a relação que vamos estabelecendo com bases de dados cada vez mais pessoais e acessíveis (Parikka, 2012: 115). Wendy Chun procura também traçar esta constelação que une mediações técnicas e economia neo-liberal, defendendo que a ideia de um software que "já está sempre lá" para permitir qualquer tipo de inscrição e acesso deriva mais das equivalências numéricas que integram os fluxos de informação no atual sistema finan-

15 Diz Wolfgang Ernst (citado em Parikka, 2012: 123) que o arquivo não tem hoje que ver com 0 armazenamento e preservação, mas sim com a transmissão. 
ceiro globalizado, do que da relação que efetivamente estabelecemos com a trama simbólica da nossa cultura (Chun, 2011: 137-140). É inevitável que neste cenário não se desencadeiem processos de subjetivação regidos pelas operações técnicas do arquivo digital e pela capacidade decisória das grandes corporações que detêm e programam 0 acesso a essa informação. Mesmo que seja promovida a imagem de que toda a nossa memória está agora armazenada e ao nosso alcance, há, de facto, uma vasta e complexa rede de dispositivos e práticas regradas que configuram a nossa memória cultural. Só no modo de funcionamento destes processos podemos discernir algumas das características essenciais da nossa relação com a trama simbólica que nos define enquanto sujeitos.

Pode mesmo seguir-se 0 argumento de Manovich, segundo o qual a base de dados computacional se tornou a forma primária de organizar e expressar a realidade. Em vez da narrativa, que foi por muitos séculos a forma primordial de ler e conferir sentido aos elementos arquivados na nossa memória cultural, as coleções estruturais de dados a que chamamos base de dados formam novos tipos de realidades informacionais possibilitadas pelo computador. A memória cultural não se impõe como um conjunto fechado de histórias que fazem parte do domínio público e que gerem as nossas estruturas simbólicas (Parikka, 2012: 114).

As estórias e a sua publicação acontecem hoje como a fala. Experienciam-se e passam, publicam-se e desaparecem - não porque o seu registo não se tenha operado, mas porque a sua leitura raramente se repetirá, porque escassamente serão re-atualizadas. As estórias devêm dados, números que só o processamento informático consegue reunir num todo, para uma leitura que, por si só, tem pouco que ver com o leitor ou o espectador de uma cultura assente na mediação analógica. A memória que retém o que nos acontece é muito diferente da memória humana com que nos lembramos, a nós mesmos, do que aconteceu.

Concomitantemente, é admirável que algumas das ações mais repetidas em todo o planeta hoje sejam construir uma história no Snapchat, publicar no Facebook, postar um tweet ou partilhar uma imagem no Instagram. A revolução digital trazida pela difusão dos novos média altera por completo a capacidade de cada um produzir e transmitir conteúdo, e nomeadamente narrativas, que partem de uma experiência pessoal do mundo.

Por outro lado, há uma transversalidade entre as plataformas e redes sociais que ligam todos estes dispositivos e que tornaram a publicação de uma estória num ato corrente, constante e repetido por milhões de pessoas a qualquer hora do dia. As estórias abundam, não só em pequenos círculos, disseminadas boca a boca, mas muitas vezes acessíveis a qualquer um que as procure ou que com elas se depare nos espaços interativos da internet. Publicar uma história é quase indistinguível, hoje, de viver e experienciar um acontecimento, especialmente devido à velocidade com que esta se regista, se codifica, se processa e é transmitida.

Não só o preço dos dispositivos capazes de o fazer se tornou acessível a uma percentagem cada vez maior da população, como esses mesmos dispositivos se miniaturizaram e, com o florescimento e expansão homéricos das redes wireless, passaram a poder ser utilizados em qualquer parte. Pode afirmar-se que a ubiquidade foi também conquistada pelos produtores, e não só pelos produtos capazes de oferecer uma experiência sensorial mediada. 
Na profusão de histórias e objetos mediados pelos arquivos digitais, e na sua diversidade, compreendemos que a memória está hoje perante o seu sublime informacional: demasiada informação para ser contida num todo, para ser sistematizada, para ser organizada num esquema valorativo universal.

Retomando a definição de cultura de Foucault, como podemos avaliar a cultura que se define por este conjunto de valores e por este tipo particular de acesso a esses mesmos valores?

É aqui que podemos retomar o carácter de experimentação que define a arqueologia dos média. A atual condição do arquivo enquanto médium tende, por um lado, a conjugar uma memória fundamentalmente numérica baseada na leitura neo-liberal e programada das inscrições sob uma base digital e, por outro lado, a fomentar interações simbólicas assentes nas bases de dados multimédia por oposição à narrativa. A arqueologia dos média procurará manipular e jogar com os dispositivos e práticas do arquivo digital, de modo a que os textos, imagens e sons que hoje podem ser armazenados, transmitidos e processados possam ser portadores e produtores de sentido. Só assim podemos esperar que os processos de subjetivação que decorrem do arquivo digital correspondem a uma memória verdadeiramente cultural.

Este é, também, o local de cruzamento entre os estudos dos média e as artes digitais. No fundo, trata-se de mobilizar o potencial da arte - enquanto conjunto das materializações simbólicas de uma cultura destinadas à experiência estética - e acoplá-lo ao arquivo enquanto médium. Como podemos recorrer ao arquivo e a todas as suas funcionalidades digitais, de modo a que a informação por ele mediada nos permita, de facto, reconhecer a humanidade das experiências aí inscritas? Como podemos encaminhar a capacidade de registo e partilha dos nossos dispositivos, o potencial de interatividade e tradução do nosso software e dos nossos programas, a organização e processamento da informação depositada nos nossos arquivos para a criação de um espaço poético, onde as narrativas, as imagens e os traços que depositamos possam ser portadores de significado? Seremos capazes de apelar à manutenção de uma cultura que defina para nós, e não apenas para as nossas máquinas, um conjunto de valores? Como podemos ter um papel nas inscrições que produzimos? E como podemos partilhá-las sem que o seu destino seja somente a manutenção de uma sociabilidade veloz, mas desalienada? Cada vez mais estamos ligados ao arquivo, mas é cada vez menos claro o sujeito que esse arquivo fará de nós.

\section{Conclusão}

Na experimentação arqueológica e artística com os novos média, e nomeadamente com 0 arquivo, há um impulso para a criação de espaços transindividuais ${ }^{16}$, que são os espaços (também técnicos) da nossa memória coletiva e do seu imaginário. Não para nos homogeneizar, ou uniformizar o nosso perfil enquanto consumidores e cidadãos, mas para potenciar o reconhecimento dos sujeitos e das individualidades que integram e transformam a nossa cultura.

Outra consequência do arquivo digital e da sua disseminação é a atenção que este desperta acerca dos arquivos pessoais, que até este momento não tinham in-

16 A relação entre a técnica e os processos ontológicos de individuação foi um dos principais temas da obra de Gilbert Simondon, como é explorado em Combes, 2012. 
tegrado os conjunto de inscrições preservadas na memória coletiva. Os múltiplos arquivos pessoais que reunimos hoje no digital e as interações entre os vários objetos, de várias fontes, que estes possibilitam, renova o interesse pelas representações que podem emergir do confronto entre estes espólios privados.

Só no último ano, uma série de iniciativas em Portugal dá conta do interesse crescente na compilação e curadoria de arquivos vernaculares para fins expositivos, que sinalizam a vontade de abrir espaços transindividuais onde se jogam processos de reconhecimento e subjetivação. Assim, por exemplo, o projeto Traça procurou reunir filmagens oriundas de arquivos familiares e pessoais, sem um chapéu temático unificador, a não ser o médium do vídeo "caseiro". A compilação destes elementos e a sua exibição em exposições públicas permite ao espetador refletir sobre 0 modo como ao longo das últimas décadas as pessoas se olharam a si mesmas, ao espaço e à sociedade que as circundava, através daquilo que optaram por filmar quando passou a ser acessível registar em vídeo experiências do dia-a-dia, das suas viagens, da família, só para nomear algumas das situações mais retratadas.

Também o Arquivo dos Diários, uma iniciativa a decorrer na biblioteca de São Lázaro em Arroios, optou por abordar a questão dos arquivos vernaculares, centrando-se na especificidade mediática do diário. 0 conjunto de experiências individuais é reunido tendo por base as características materiais deste médium que permite um registo confessional muito próprio. Estas não podem reescrever a cada relato 0 curso dos acontecimentos históricos. Mas estas formas de arquivo estimulam 0 reconhecimento das experiências individuais e humanas que povoam a História, através do confronto com o que outros seres humanos optaram por registar nos seus cadernos pessoais.

Com o projeto Estórias: Portugal-África, procurámos que a construção desses espaços transindividuais se fizesse também através da criação de um interface (ainda em desenvolvimento). Os arquivos VHS ou de diários conservavam o tempo, mas os arquivos técnicos do presente podem ser descritos como arquivos em movimento, dinâmicos e em permanente mudança (Parikka, 2012). Arquivar sobrepõe-se ao arquivo, porque 0 objetivo não é racionalizar o conjunto das imagens e narrativas, mas interagir com sobreposições do nosso imaginário coletivo. Como peça de artes digitais, o seu médium é o arquivo, acessível ao público, que tanto pode ser espetador, como produtor dos seus conteúdos.

A omnipresença do arquivo digital na contemporaneidade, o seu dinamismo, o seu papel na manutenção da nossa memória cultural e o seu cruzamento com as práticas artísticas que 0 adoptam enquanto médium são questões que motivam este projeto. Pode o reconhecimento do nosso imaginário comum ser promovido pela implementação de uma plataforma web contributiva para a recolha de histórias? Que representações podem ser mediadas por uma base de dados multimédia (de texto, foto, desenho, vídeo, som) sobre memórias e experiências, histórias de ligação entre as culturas portuguesa e africanas, com raíz em diferentes espaços e temporalidades?

Uma vez que o imaginário comum entre Portugal e África tende a ser definido pela história extraída dos arquivos tradicionais, faz todo o sentido encetar uma arqueologia dos média assente na experimentação e na criação artística, e que se debruce sobre 0 arquivo digital e as representações multiformes e heteróclitas que daí emergem. 
Com as possibilidades oferecidas pelo digital e pela natureza das suas inscrições, arquivar pode ser também, hoje, reconhecer a fluidez e diversidade inerentes às nossas identidades, tecnicamente aparelhadas, portuguesas e africanas.

\section{REFERÊNCIAS BIBLIOGRÁFICAS}

Borges, Jorge Luís "Sobre o Rigor na Ciência", in História Universal da Infâmia, trad. de José Bento (Lisboa: Assírio e Alvim, 1982)

Chun, Wendy Hui Kyong, "The Enduring Ephemeral, or the Future Is a Memory," Critical Inquiry 35, no. 1 (Chicago, IL: University of Chicago Press, 2008, p. 148-171)

Chun, Wendy Hui Kyong (2011) Programmed Visions: Software and Memory (Cambridge, MA: The MIT Press)

Combes, Muriel (2012) Gilbert Simondon and the Philosophy of the Transindividual (Cambridge, MA: The MIT Press)

Ernst, Wolfgang (2013) Digital Memory and the Archive (Minneapolis, MN: University of Minnesota Press)

Foucault, Michel (2006) A Hermenêutica do Sujeito: Curso dado no Collège de France (198182)(São Paulo: Martins Fontes)

Foucault, Michel (2014) A Arqueologia do Saber (Lisboa: Edições 70)

Godelier, Maurice (2007) Au fondement des sociétés humaines (Paris: Albin Michel)

Leroi-Gourhan, André (2002) 0 Gesto e a Palavra 2 - Memória e Ritmos, coleção "Perspetivas do Homem" (Lisboa: Edições 70)

Manovich, Lev (2013) Software Takes Command (New York, NY: Bloomsbury Academic

McLuhan. Marshall (2008) Compreender os Meios de Comunicação: Extensões do Homem (Lisboa: Relógio d’Água)

Parikka, Jussi (2012) "Archive Dynamics and Software Culture" in What is Media Archaeology (Malden, MA: Polity Press)

Rodrigues, José Damião e Rodrigues, Casimiro, "Introdução" in Representações de África e dos Africanos na História e Cultura - Séculos XV a XXI, coleção "Estudos e Documentos" (Ponta Delgada: 2011, Centro de História de Além-Mar)

Siegert, Bernhard "Cultural Techniques: Or the End of the Intellectual Postwar Era in German Media Theory" in Theory, Culture and Society 30 (6) (Londres: Sage, Novembro 2013)

Vismann, Cornelia, Files: Law and Media Technology, coleção "Meridian: Crossing Aesthetics" (Stanford, CA: Stanford University Press, 2008)

Winthrop-Young, Geoffrey, "Cultural Techniques: Preliminary Remarks" in in Theory, Culture and Society 30 (6) (Londres: Sage, Novembro 2013, p. 9-10) 